\title{
A BOTTOM-UP APPROACH FOR DISTRICT-LEVEL DOMESTIC ENERGY DEMAND FORECASTING Amin Amin ${ }^{1,2 *}$, Monjur Mourshed ${ }^{1}$
}

\author{
${ }^{I}$ School of Engineering, Cardiff University, Cardiff, CF24 3AB, United Kingdom \\ ${ }^{2}$ Department of Architecture, Faculty of Fine Arts, Helwan University, Cairo, Egypt \\ *AminA8@cardiff.ac.uk
}

\begin{abstract}
Keywords: COMMUNITY ENERGY MODELLING, PHYSICAL-BASED MODELLING, ELECTRICAL ENERGY DEMAND, DEMAND RESPONSE
\end{abstract}

\begin{abstract}
An accurate district electricity load is crucial to ensure the optimal design and operation of Distributed Energy System (DES). Therefore, a bottom-up physics-based model of district-level thermal and electrical energy demand was developed in this research for estimating sub-hourly energy demand of buildings at a community/district level to support the mitigation of peak energy demand and to save energy and cost. The main factors influencing district energy demand considered in developing the model include: building construction and materials, equipment and appliances, local microclimate, and social and occupancy behaviours. A key feature of the model is the use of a sub-hourly updated weather forecast in order to improve prediction accuracy, and the estimation of household electrical appliance demand based on occupancy patterns and time of use (ToU).

The model provides accurate predictions of the temporal electricity demand variations and the peak power load. The results of the study are used for (i) analysing the impact of energy efficiency schemes and demand response on the grid; (ii) the planning and operation of district-level low-voltage grid considering the flexibility offered by the houses.
\end{abstract}

\section{Introduction}

Domestic energy consumption accounts for $19 \%$ of the total $\mathrm{CO} 2$ emissions in the UK, which has fallen by $17 \%$ between 1990 and 2019 [1]. The Government aims to achieve an $80 \%$ reduction of greenhouse gas emissions by 2050 as committed through the Climate Change Act 2008 [2]. Increasing decentralisation of energy infrastructure and the penetration of intermittent renewable energy in the supply system, as well as the rise in energy prosumers require pro-active demandside management for grid operational efficiency and stability [3]. Considering the diversity of domestic buildings, detailed district-level energy demand profiles are, therefore, critical prerequisites for the design, expansion and management of the electricity grid. Accurate prediction of high-resolution (hourly/sub-hourly) household energy consumption profiles are also essential for district-level grid balancing, energy efficiency and the effective integration of distributed generation and demand response strategies [4].

Real-time Energy and Environmental Forecasting and Simulation (REEFS) is a main functional component of the TABEDE project, a 3-year project funded by the European Commission's Horizon 2020 program that aims to allow buildings to integrate energy grid demand response (DR) schemes. REEFS provides predictions for weather, electricity demand and generation profiles for buildings and neighbourhoods through integrating data-driven models and physics-based simulation models [5]. REEFS-Simulation Environment (REEFS$\mathrm{SE}$ ) is one of REEFS forecasting services that provides dayahead profiles for electricity load, use and generation ranging from device to district level based on a detailed whole building simulation program. In this research, we present a bottom-up physics-based model of district-level thermal and electrical energy demand that was developed in REEFS-SE for estimating sub-hourly energy demand of buildings at a community/district level to support the mitigation of peak energy demand and to save energy and cost.

\section{Methodology}

The simulation environment aims to develop a physics-based forecasting model to predict the energy consumption from electrical appliances and the total electricity demand for each unit in the study area. The forecasting model is based on EnergyPlus, which is recognised as one of the most popular and comprehensive building energy simulation software for calculating the building thermal performance response to weather [6]. The model includes two inputs that are required for running the simulation: (i) the building energy model formatted as Input Data File (IDF) that contains data related to building characteristics, including building physics information, construction materials, internal loads, schedules and occupancy profiles; (ii) weather information for the location of the building in an EnergyPlus Weather (EPW) format which usually represents the typical meteorological year for the location. 
The key features of the model is the use of a sub-hourly updated weather forecast in order to improve prediction accuracy, and the estimation of household electrical appliance demand based on occupancy patterns and time of use (ToU). The contribution of the household's appliances to the daily and peak demand is also considered. The modelling approach is developed on real data of a part of Penarth Heights neighbourhood and its grid topology in Vale of Glamorgan, Cardiff, UK.

In this section, the key elements and steps taken to construct the simulation environment are presented. These include the number and type of houses, and the occupancy profiles in the study area. Besides, the number, type and energy load profiles of the electric appliances included in the model.

\subsection{Building information}

The network of the study neighbourhood is composed of a single MV/LV transformer to which three feeders are connected. One single grid feeder was selected for the simulations in order to maintain sufficient computing time. The feeder comprises 121 units distributed over eight dwelling archetypes, including terraced houses and apartment buildings that enable a fair representation of district-level electricity demand. Clustering techniques to identify building archetypes depending on feature identification variables such as building area, shape, type, orientation and occupancy number to reduce the number of simulations. Detail dwelling physics information, including areas, number of rooms, counts and number of units within these dwellings, are listed in Table 1. Meanwhile, the construction properties and materials were derived according to the new Part L of the 2010 building regulations (England and Wales) for the conservation of fuel and power in new and existing dwellings [7].

Table 1 Dwelling archetypes modelled in the simulation environment

\begin{tabular}{|c|c|c|c|c|c|c|}
\hline Type & Archetype & ID & Room & $\begin{array}{l}\text { Area } \\
{\left[\mathrm{m}^{2}\right]}\end{array}$ & N.D.* & Units \\
\hline \multirow[t]{9}{*}{ House } & The Maritime & HSO3 & 3 & 62 & 6 & 6 \\
\hline & The Mulberry & HS04 & 3 & 76 & 10 & 10 \\
\hline & The Verve & HS05 & 3 & 88 & 7 & 7 \\
\hline & The Phoenix & HS06 & 4 & 126 & 14 & 14 \\
\hline & $\mathrm{HA}^{* *}$ & HA01 & 2 & 62 & 1 & 1 \\
\hline & & HA02 & 2 & 62 & 19 & 19 \\
\hline & & HA03 & 2 & 62 & 4 & 4 \\
\hline & & HA04 & 3 & 76 & 9 & 9 \\
\hline & & HA06 & 4 & 126 & 7 & 7 \\
\hline \multirow[t]{3}{*}{ Apartment } & $\mathrm{HA}^{* *}$ & APT_C & $1-2$ & $45-64$ & 1 & 12 \\
\hline & Baron House & APT_B & 2 & $53-62$ & 6 & 24 \\
\hline & Vantage House & APT_F & $1-2$ & $45-53$ & 1 & 8 \\
\hline Total & & & & & & 121 \\
\hline
\end{tabular}

\subsection{Occupancy and schedules}

The occupancy number and behaviours play important roles to decide the energy consumption pattern. There are three main types of household in Vale of Glamorgan, Cardiff, distributed on $32.3 \%$ for a single person household, $35.2 \%$ a couple without children and around $32.5 \%$ for two adults with children [8]. The number of occupants for each unit is estimated based on the number of rooms and the household type distribution, as shown in Table 2. On the other hand, the presence of occupants reflects on the time of use of residential appliances. Therefore, daily occupancy profiles in the district are derived based on active occupancy patterns from the BRE Domestic Energy Model (BREDEM) [9] and from the UK Time of Use Survey 2015 [10]. Occupancy behaviour scenarios were assigned to units according to daily concluded occupancy profiles and the probability of occupancy state adopted from Argon et al. [11], as shown in Figure 1.

Table 2 Occupancy distribution by household type

\begin{tabular}{|c|c|c|c|c|c|}
\hline \multirow[t]{2}{*}{ Archetype } & \multirow[t]{2}{*}{ Occ. $^{1}$} & \multirow[t]{2}{*}{ Units } & \multirow{2}{*}{$\begin{array}{l}\text { Rate } \\
{[\%]}\end{array}$} & \multicolumn{2}{|c|}{ Household } \\
\hline & & & & Size & Rate [\%] \\
\hline APT_F, APT_C, APT_B & 1 & 11 & 9.1 & 1 & 32.3 \\
\hline $\begin{array}{l}\text { APT_F, APT_C, APT_B, } \\
\text { HA01, HA02, HA03 }\end{array}$ & 2 & 57 & 47.1 & 2 & 35.2 \\
\hline HA04, HS03, HS04, HSO5 & 3 & 32 & 26.4 & 3 & 14.8 \\
\hline HA06, HS06 & 4 & 21 & 17.4 & +4 & 17.7 \\
\hline Total & & 121 & 100 & & 100 \\
\hline
\end{tabular}

${ }^{1}$ Number of Occupants

(A) Weekday

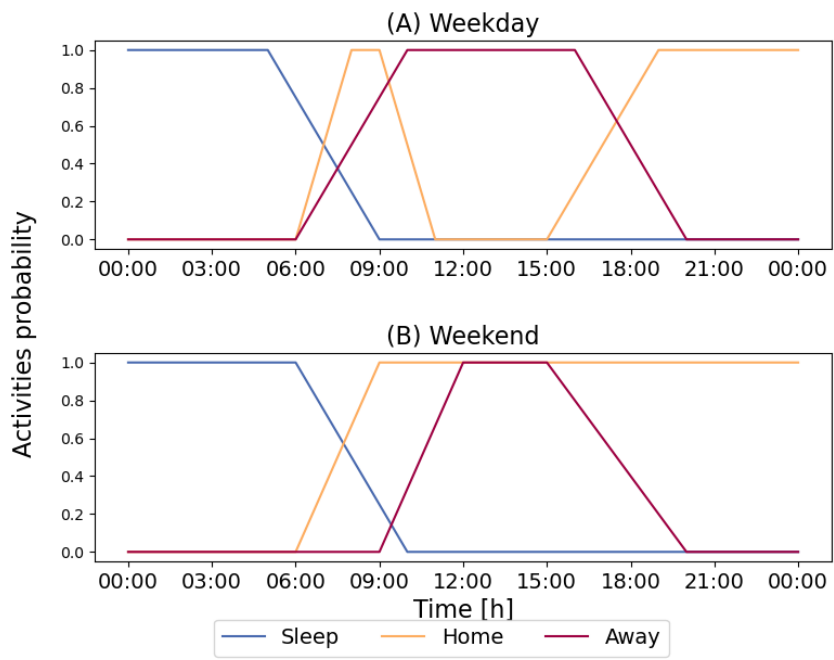

Fig. 1 Probability of occupancy states in the UK residential houses for weekdays and weekends

\subsection{Electrical load modelling}

The individual electrical appliance loads and numbers in each unit are the key elements for estimating the district electricity demand since heating systems among the district archetypes 
are based on gas boilers. A multi-step process has been followed to address these estimates based on an electrical load scenario for domestic appliances, as shown in Figure 2, as follows:

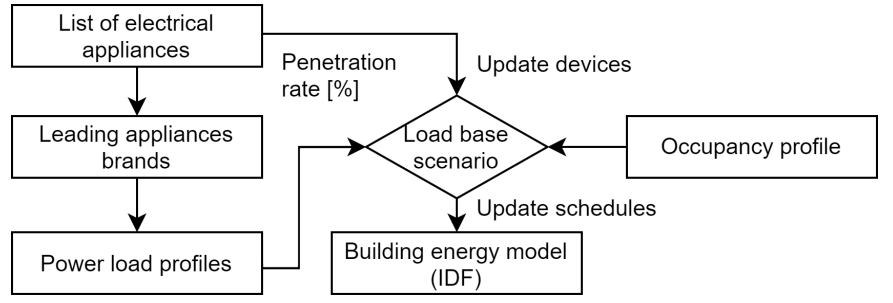

Fig. 2 Schematic diagram for generating the scenario of the appliances' ownership

- First, penetration rates for a list of common electrical devices including hot, cold, wet, brown, and miscellaneous appliance groups in residential houses have been estimated according to household ownership rates for domestic appliances in the UK $[12,13]$, as illustrated in Figure 3. Then, an ownership scenario for the simulation environment is generated by distributing those domestic appliances across the 121 units.

- Secondly, groups of different appliances energy information for each appliance were set according to leading appliances brands in the UK market. After that, power load profiles were calculated based on the rated power and energy consumption for each appliance in those groups. Figure 4 illustrates different power load profiles for a washing machine, dishwasher and cloth dryer randomly selected from wet appliances group.

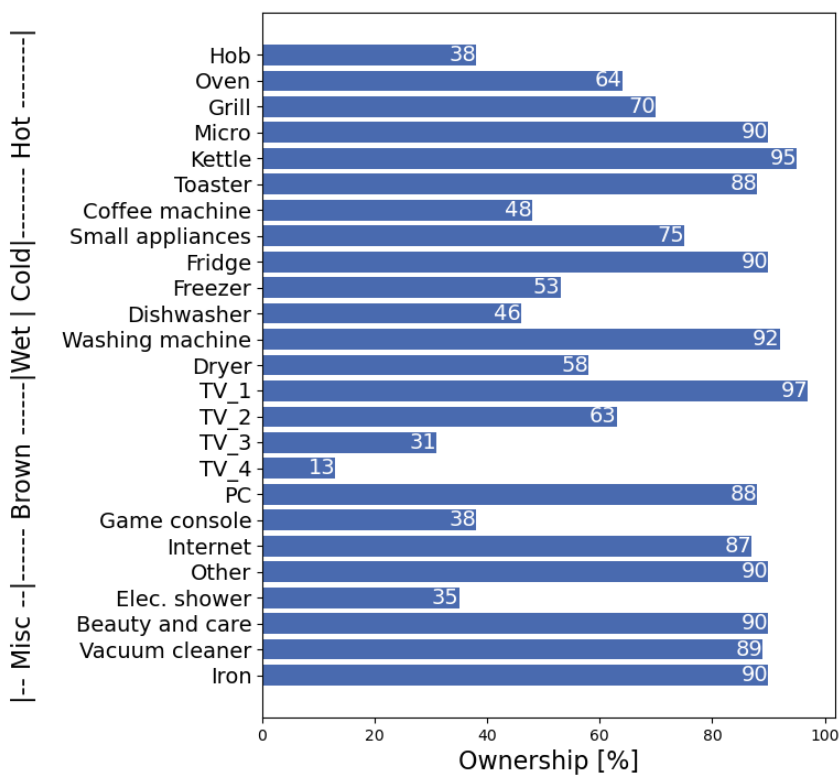

Fig. 3 Penetration rates for common household electrical appliances and devices

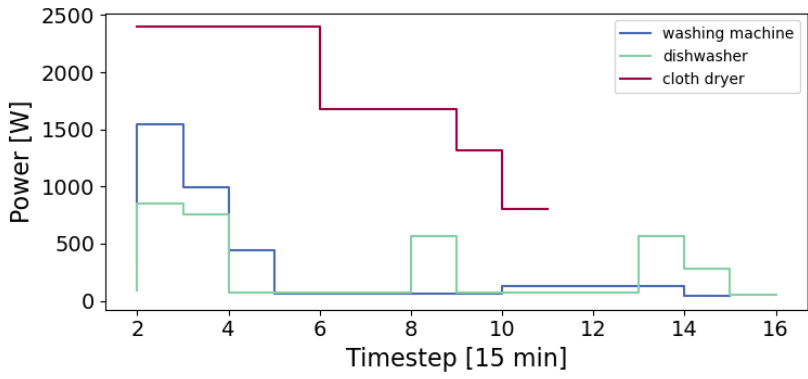

Fig. 4 Examples of power load profiles for different wet appliances

Finally, daily power load profiles for electrical appliances at district units are developed basis on the usage frequency and period adopted from the BRE Energy follow-up survey Report [13] and active probabilities adopted from the UK Time of Use Survey scenarios [14], as shown in Figure 5. In that way, each unit has a full set of electrical load profiles aligned with the appliances and devices it contains. Meanwhile, the information for lighting power was set according to CIBSE SLL Lighting Guide LG09: Lighting for communal residential buildings [15].

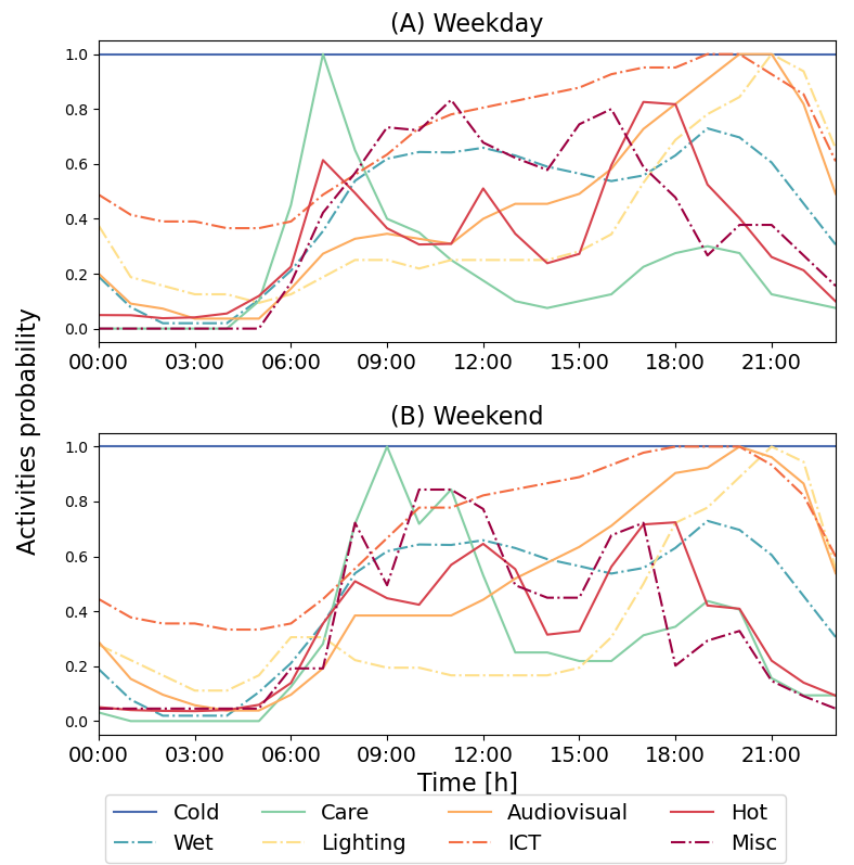

Fig. 5 Activities of electrical appliances in the UK residential houses

\subsection{Weather information}

Weather data is a key input required for adequate building thermal simulations, which significantly influences on the whole building energy performance. Most of the available weather data files (EPW) describe typical meteorological conditions that might include uncertainties due to use an old period or oneperiod of records for generation and missed weather variances of recent years [16]. 
The EPW file contains 29 weather variables measurements, among which nine important variables were used in the simulations. These key variables can be sorted into four groups: (1) outdoor air conditions: dry-bulb temperature, dew-point temperature, relative humidity, and atmospheric pressure; (2) solar radiation: direct normal solar radiation and diffuse horizontal solar radiation; (3) sky radiation: horizontal infrared radiation; and (4) wind conditions: wind direction and wind speed.

Real-time and historical data for weather parameters required to run energy simulations were retrieved from a local automatic weather station (AWS) installed at the district location in Penarth. Meanwhile, forecast data are obtained from a weather API online service in 15-min time resolution. An algorithm to accommodate the meteorological data was used to update the EPW file with the forecast and the real-time data stored in the database.

\subsection{Energy forecasting model}

The development of the simulation-based forecasting model has multi-step processes to predict electricity demands at device level up to district level, as illustrated in Figure 6. The energy model is being operated through algorithms to collects building information, including building type, orientation, and the number of occupants based on the input (plot number/node label). After that, the model generates occupancy profiles and operation schedules of electrical appliances according to pre-defined occupant behaviour scenarios, and electrical load scenarios, respectively. Then, it detects IDF(s) of the required building(s) from the archived IDFs database for district archetypes, and updates occupancy profiles, electrical appliances ownership and operation schedules based on the scenario of electrical appliances.

On the other hand, the model allows accommodating an algorithm to collect real-time and forecasts for weather variables for the location of the building(s)/district from the weather API (REEFS). Then, it estimates the missing parameters through mathematical models. After that, this weather data is used to update the EPW file and determine the run period for the simulation. The results of the simulation environment include predictions for the next 24-hour electricity profiles for each unit, including: (i) the total electricity demands; (ii) the power load for all electrical appliances; (iii) PV panel generation profile (if installed).

\section{Results}

Multiple forecasting simulations for a daily electricity load profile for district residential units have been performed, for a weekday, using the developed framework. Figure 7 illustrates the simulation environment results of 24-hour predictions for electricity loads of individual residential units with a $15-\mathrm{min}$ time resolution, and the average daily electricity load profile for domestic households within the study area. It shows that two high demand periods are due during the morning-time (6 to $9 \mathrm{am}$ ) when occupants wake up and get ready to go out, and when people come back home at the night-time (6 pm to midnight).

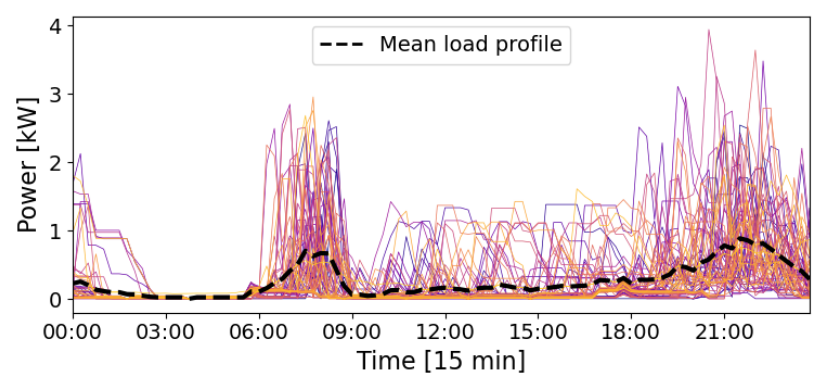

Fig. 7 An example of daily electricity load forecasts, for a weekday, for 121 residential units. The dashed line represents the average electricity load profile for domestic households in the Penarth district

In order to validate the simulation environment forecasting approach, statistical comparisons have been performed

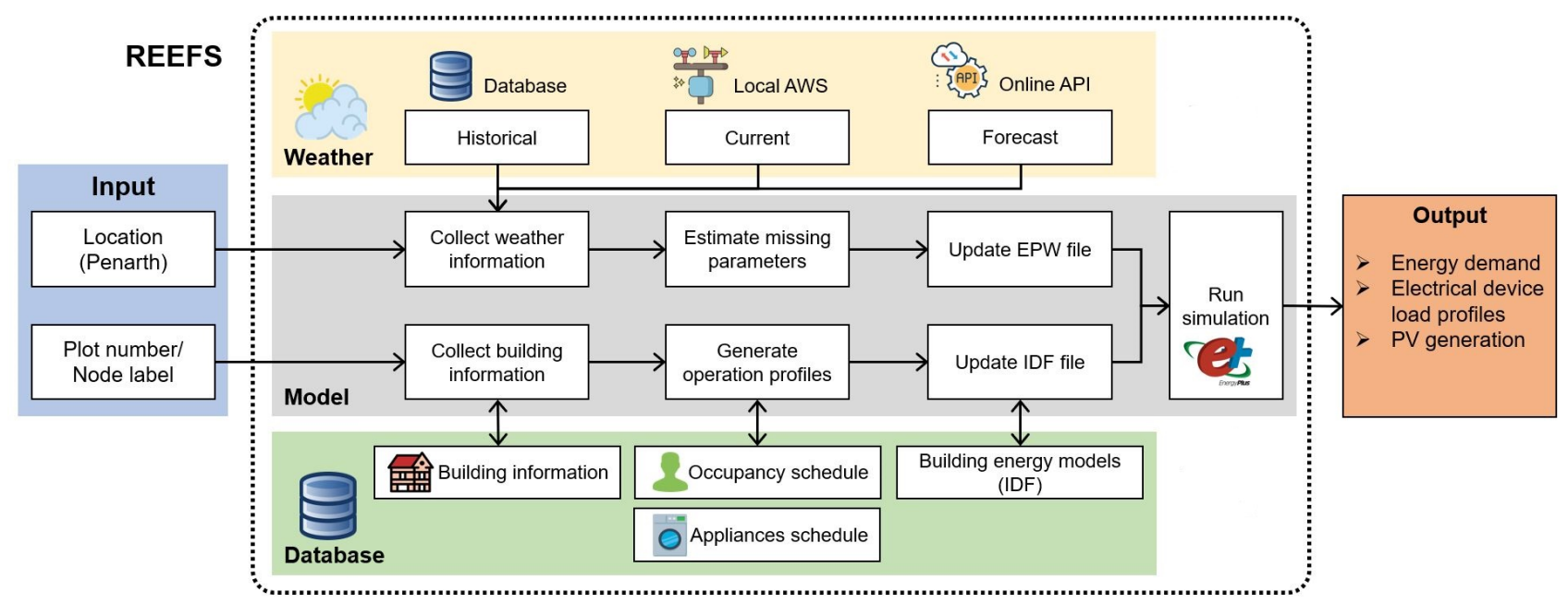

Fig. 6 A schematic diagram for the simulation-based forecasting model for district electricity loads in REEFS Simulation Environment 
between the forecast data and the typical household electricity consumption data according to the UK Household Electricity Survey (HES) that was undertaken to monitor the electrical power load and energy consumption based on a sample of 251 households []. The average annual consumption from the HES data for all household types is $71 \mathrm{kWh}$ per meter square, while the averages based on dwelling types are 75, 66 and 77 $\mathrm{kWh}$ per meter square for terraced, detached houses and flats, respectively.

Table 3 summaries statistical indicators for the simulationbased forecasting model outputs. The average daily electricity power demands from the forecasting model are about 12.5 KWh, while ranges between 10.4 to $12.4 \mathrm{KWh}$ based on HES data calculations. The total electricity demand for the 121 units is $829.8 \mathrm{kWh}$. The simulation-based model gives a high forecasting accuracy on scales of building and district level, which ranges from 0.79 up to 0.99 for individual indicators and from 0.85 to 0.97 for the whole district demand.

Table 3 Electricity demand forecasts validation

\begin{tabular}{llllll}
\hline Indicator & Results & $\begin{array}{l}\text { HES }^{1} \\
\text { Area }\end{array}$ & Household & Area & Household \\
\hline Min & 6.48 & 6.53 & 7.16 & 0.99 & 0.91 \\
Max & 21.71 & 19.91 & 21.35 & 0.79 & 0.98 \\
Mean & 12.57 & 10.49 & 12.41 & 0.80 & 0.99 \\
Total & 829.80 & 717.98 & 852.55 & 0.85 & 0.97 \\
\hline
\end{tabular}

${ }^{1}$ Calculation based on average annual consumption per meter square based on household and dwelling types

\section{Conclusion}

A domestic electricity demand forecasting model based on detailed physical model simulations has been presented. In this study, key factors that influence the household electricity consumption in the UK have been investigated, including the appliance ownership and usage pattern and periods data. The simulation model maps occupant activities to the appliance use and stochastically generates individual appliance operation schedules with a 15-min time resolution, which was developed based on national appliance ownership statistics, individual appliance electricity consumption and Time-of-Use data.

The model provides accurate predictions of the temporal electricity demand variations and the peak power load. The results of the study are used for (i) analysing the impact of energy efficiency schemes and demand response on the grid; (ii) the planning and operation of district-level low-voltage grid considering the flexibility offered by the houses.

Overall, the modelling framework demonstrates an effective method of domestic electricity use forecasting with the capability to scale down to individual buildings and appliances level that would be useful for stakeholders involved in buildings energy demand, decision-makers and grid management.

\section{Acknowledgements}

The work in this study was carried out in the framework of the European Union's H2020 project "TowArds Building rEady for Demand rEsponse (TABEDE)" under Grant Agreement No. 766733.

\section{References}

[1] Penistone, A.: '2019 uk greenhouse gas emissions, provisional figures', Department for Business, Energy \& National Strategy, National Statistics, OGL, 2019

[2] Department of Energy and Climate Change: 'The UK low carbon transition plan: national strategy for climate and energy', DERECHO INTERNACIONAL, 2009

[3] Kristina, O., Ralph E., Viktor, D.: 'Integration of decentralized energy systems in neighbourhoods using the energy hub approach', Applied Energy, 2015

[4] Ian, R., Murray, T., David, I., Conor, C.: 'Domestic electricity use: A highresolution energy demand model', Energy and buildings, 42, (10), 2010, pp 1878-1887

[5] Amin, A., Kem, O., Gallegos, P., et al: 'An intelligent infrastructure for enabling demand-response ready buildings', In International Conference on Applied Energy (ICEA) 2020, Bangkok/Virtual, 2020

[6] Mahabir, B., Som, S., Joshua, N.: 'Evaluation of weather datasets for building energy simulation', Energy and Buildings, 49, 2012, pp 109-118

[7] Wei, P., Helen, G.: 'Building regulations in energy efficiency: Compliance in england and wales', Energy Policy, 45, 2012, pp 594-605

[8] StatsWales: 'Household estimates for wales - households by type by local authority', 2019

[9] Henderson, J., Hart, J.: 'Bredem 2012-a technical description of the bre domestic energy model', Building Research Establishment, UK, 2012

[10] Jonathan, G.: 'United kingdom time use survey', 20142015, 2017

[11] Victoria, A., Stephanie, G., Peter, W., et al: 'Developing english domestic occupancy profiles', Building Research \& Information, 47, (4), 2019, pp 375-393

[12] Statista GmbH: 'Household appliances ownership in the uk 2020', 2020

[13] Hulme, J., Beaumont, A., Summers, C.: 'Energy followup survey 2011. report 9: Domestic appliances, cooking \& cooling equipment', Watford, UK, 13, 2013

[14] Jean-Paul, Z., Matt, E., Jonathan, G., et al: 'Household electricity survey: A study of domestic electrical product usage', Intertek Testing \& Certification Ltd, 2012, pp 213-214

[15] LG09 CIBSE. Sll lighting guide 09: Lighting for communal residential buildings. The Society of Light and Lighting (part of CIBSE), Page Bros.(Norwich), 2013

[16] Ying, C., Da Y., Tianzhen, H., et al: 'Comparison of typical year and multiyear building simulations using a 55-year actual weather data set from china', Applied energy, 195, 2017, pp 890-904 